\title{
Massive Xanthomatosis and Atherosclerosis in Cholesterol-fed Low Density Lipoprotein Receptor-negative Mice
}

\author{
Shun Ishibashi, * Joseph L. Goldstein, * Michael S. Brown, * Joachim Herz, " Dennis K. Burns," \\ Departments of * Molecular Genetics and ${ }^{\ddagger}$ Pathology, University of Texas Southwestern Medical Center at Dallas, Dallas, Texas 75235
}

\begin{abstract}
Mice that are homozygous for a targeted disruption of the LDL receptor gene ( $L D L R^{-1-}$ mice) were fed a diet that contained $1.25 \%$ cholesterol, $7.5 \%$ cocoa butter, $7.5 \%$ casein, and $0.5 \%$ cholic acid. The total plasma cholesterol rose from 246 to $>1,500 \mathrm{mg} / \mathrm{dl}$, associated with a marked increase in VLDL, intermediate density lipoproteins (IDL), and LDL cholesterol, and a decrease in HDL cholesterol. In wild type littermates fed the same diet, the total plasma cholesterol remained $<160$ $\mathrm{mg} / \mathrm{dl}$. After $7 \mathrm{mo}$, the $L D L R^{-1-}$ mice developed massive xanthomatous infiltration of the skin and subcutaneous tissue. The aorta and coronary ostia exhibited gross atheromata, and the aortic valve leaflets were thickened by cholesterol-laden macrophages. No such changes were seen in the $L D L R^{-1-}$ mice on a normal chow diet, nor in wild type mice that were fed either a chow diet or the high-fat diet. We conclude that LDL receptors are largely responsible for the resistance of wild type mice to atherosclerosis. The cholesterol-fed $L D L R^{-/-}$mice offer a new model for the study of environmental and genetic factors that modify the processes of atherosclerosis and xanthomatosis. (J. Clin. Invest. 1994. 93:1885-1893.) Key words: lipoprotein metabolism • hypercholesterolemia • liver receptors • targeted gene disruption • animal model for atherosclerosis
\end{abstract}

\section{Introduction}

Fulminant atherosclerosis, accompanied by xanthomatous accumulation of cholesterol in skin and tendons, is the hallmark of homozygous familial hypercholesterolemia (FH). ${ }^{1}$ In this disease an absence of functional LDL receptors leads to an accumulation of cholesterol-rich lipoproteins in plasma and a secondary deposition of cholesteryl esters in macrophage foam cells throughout the body. Cutaneous xanthomas are present at birth, and atherosclerotic involvement of the aortic root and coronary arteries causes symptoms in childhood (reviewed in reference 1 ).

A new animal model for homozygous $\mathrm{FH}$ was developed recently through targeted disruption of the LDL receptor gene in mice (2). Homozygous LDL receptor-deficient mice $\left(L D L R^{-1-}\right)$ manifested delayed clearance of VLDL, intermediate density lipoproteins (IDL), and LDL from plasma. As a

Received for publication 22 November 1993 and in revised form 4 January 1994.

1. Abbreviations used in this paper: $\mathrm{FH}$, familial hypercholesterolemia; IDL, intermediate density lipoproteins.

J. Clin. Invest.

(C) The American Society for Clinical Investigation, Inc.

0021-9738/94/05/1885/09 \$2.00

Volume 93, May 1994, 1885-1893 result, the total plasma cholesterol level rose from $108 \mathrm{mg} / \mathrm{dl}$ in wild type mice to $236 \mathrm{mg} / \mathrm{dl}$ in $L D L R^{-/-}$mice, owing to a seven- to ninefold increase in IDL and LDL. Adult $L D L R^{-1-}$ mice did not exhibit gross evidence of xanthomatosis as in the human disease, and the extent of aortic atherosclerosis was minimal.

The relatively mild pathologic manifestations in the $L D L R^{-/-}$mice are likely attributable to the failure of the plasma cholesterol to reach the levels observed in humans with homozygous FH who have total plasma cholesterol of $600-$ $1,000 \mathrm{mg} / \mathrm{dl}$ (1). This difference may be explained by the fact that livers of mice, unlike those of humans, produce two versions of apolipoprotein B, apo B-100 and apo B-48, both of which are incorporated into VLDL (3-5). In humans and mice, VLDLs that contain apo B-100 give rise to apo B-100containing remnant particles (also called IDL) that are cleared from plasma almost entirely by LDL receptors $(6,7)$. In LDL receptor deficiency these remnants remain in plasma where they are converted to LDL. Mouse livers also produce VLDLs that contain apo B-48. In humans this particle is secreted only in intestinal chylomicrons (3-5). apo B-48 containing VLDLs, like intestinal chylomicrons, generate remnants that can bind to a second receptor, designated the chylomicron remnant receptor $(8,9)$. Chylomicron remnants (and presumably VLDL remnants) that contain apo B-48 are cleared rapidly even when LDL receptors are absent $(10,11)$, and they do not give rise to appreciable amounts of LDL (12). This clearance is attributable to the ability of apo B-48 particles to accept large amounts of apo $\mathrm{E}$, which is a ligand for the chylomicron remnant receptor as well as the LDL receptor. In adult mice $\sim 70 \%$ of hepatic apo B is in the B-48 form (3), and this is believed to account for the relatively mild elevation of $\mathrm{LDL}$ levels in $L D L R^{-/-}$ mice (2).

In contrast to wild type mice, $L D L R^{-/-}$mice demonstrated markedly elevated plasma cholesterol levels when fed modest amounts of cholesterol and saturated fat (2). A diet containing $0.2 \%$ cholesterol and $10 \%$ coconut oil raised the plasma cholesterol slightly to $149 \mathrm{mg} / \mathrm{dl}$ in wild type mice and markedly to $425 \mathrm{mg} / \mathrm{dl}$ in $L D L R^{-1-}$ mice. The increased cholesterol was contained in IDL as well as in LDL. We interpret this finding to indicate that normal mice produce sufficient LDL receptors to clear the increased production of cholesterol-rich VLDL that occurs upon cholesterol feeding. The $L D L R^{-/-}$mice cannot clear these particles, and hence they are diet hyperresponsive (2). The ability of wild type mice to clear large amounts of lipoproteins from plasma may explain their resistance to atherosclerosis and xanthomatosis induced by cholesterol feeding.

In the current studies we sought to determine whether an even greater increase in plasma cholesterol could be achieved by the feeding of an even more lipid-rich diet to the $L D L R^{-/-}$ mice, and whether this would lead to the secondary manifestations observed in humans with homozygous FH. The results indicate that fat-fed $L D L R^{-/-}$mice develop striking xantho- 
Table I. Plasma Cholesterol Levels in Three Genotypes on Two Different Diets

\begin{tabular}{lccccr}
\hline & \multicolumn{2}{c}{ Normal chow } & & \multicolumn{2}{c}{$1.25 \%$ cholesterol } \\
\cline { 2 - 3 } \cline { 5 - 6 } \cline { 5 - 6 } Genotype & Male & Female & & Male & Female \\
\hline Wild type & $122 \pm 8$ & $101 \pm 12$ & & $132 \pm 15$ & $154 \pm 12$ \\
Heterozygotes & $159 \pm 7$ & $133 \pm 10$ & & $288 \pm 53$ & $264 \pm 55$ \\
Homozygotes & $225 \pm 27$ & $267 \pm 22$ & & $1,583 \pm 120$ & $2,177 \pm 72$ \\
& & & & & \\
\hline
\end{tabular}

Total plasma concentrations were measured from four or five male and female mice (nonfasting) that were wild type $(+/+)$, heterozygous $(+/-)$, or homozygous $(-/-)$ for a disrupted LDL receptor allele fed either a normal chow diet or a $1.25 \%$ cholesterol chow diet for $2 \mathrm{wk}$. The values are mean \pm SE. The mice were 6 mo of age at the time of blood collection.

matous infiltration of skin and subcutaneous tissues as well as fulminant aortic atherosclerosis, thereby providing a model for the clinical features of homozygous FH.

\section{Methods}

General methods. Blood was sampled from the retro-orbital plexus as described (2). Plasma cholesterol and triglycerides were determined enzymatically with assay kits obtained from Boehringer Mannheim Biochemicals (Indianapolis, IN) and Sigma Chemical Co. (St. Louis, MO), respectively. Plasma lipoprotein analysis was performed by fast performance liquid chromatography (FPLC) gel filtration as described (2), except that the plasma lipoprotein fraction $(d<1.215 \mathrm{~g} / \mathrm{ml})$ was delipidated with ethanol/ether ( $1: 1)$, omitting trichloroacetic acid precipitation.

Mice. LDL receptor knockout mice $\left(L D L R^{-/-}\right)$were created by homologous recombination as described (2). Experiments were per-

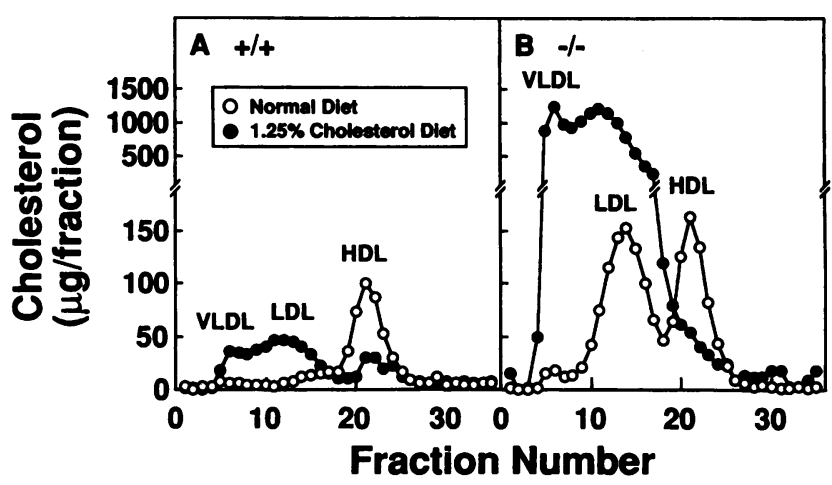

Figure 1. FPLC profiles of plasma lipoproteins from wild type $(A)$ and $L D L R^{-1-}$ mice $(B)$ fed different diets. Mice with the indicated genotype ( $n=6$; three males and three females) were fed either a normal chow diet (O) or a $1.25 \%$ cholesterol $(\bullet)$ diet for $6 \mathrm{mo}$. Blood was obtained from nonfasted animals, the $d<1.215 \mathrm{~g} / \mathrm{ml}$ lipoprotein fraction of pooled plasma from each group was subjected to gel filtration on FPLC, and the cholesterol content of each fraction was measured as described in Methods. Note the break in the scale in $B$. The mice were $10 \mathrm{mo}$ of age at the time of blood collection. The total plasma cholesterol levels (mean values) in the wild type mice on the normal and cholesterol diets were 99 and $163 \mathrm{mg} / \mathrm{dl}$, respectively. The comparable values in the $L D L R^{-1-}$ mice were 291 and $2,278 \mathrm{mg} / \mathrm{dl}$. formed with $F_{2}$ generation descendants that are hybrids between the $\mathrm{C} 57 \mathrm{Bl} / 6 \mathrm{~J}$ and $129 \mathrm{~Sv}$ strains. Wild type littermates $\left(L D L R^{+/+}\right)$were used as controls. Mice were maintained on 12-h dark and 12-h light cycles and were allowed access to food and water ad libitum.

Diets. Two diets were used. (a) A normal chow diet (Teklad 4\% mouse/rat diet 7001; Harlan Teklad Premier Laboratory Diets, Madison, WI) that contained $4 \%(\mathrm{wt} / \mathrm{wt}$ ) animal fat with $<0.04 \%$ (wt/ wt) cholesterol. (b) A 1.25\% cholesterol diet (three parts of the normal chow diet mixed with one part of a $30 \%$ cocoa butter, $5 \%$ cholesterol diet; TD 78399; from Harlan Teklad) adjusted to contain 7.5\% (wt/ wt) cocoa butter, $1.25 \%$ cholesterol, $7.5 \%$ casein, and $0.5 \%$ (wt/wt) sodium cholate.

Tissue morphology. Mice were assigned sequential identification numbers and killed by cervical dislocation after blood was collected from the retro-orbital plexus. Hearts and aortas were exposed and removed en bloc in the fresh state for morphological evaluation by an
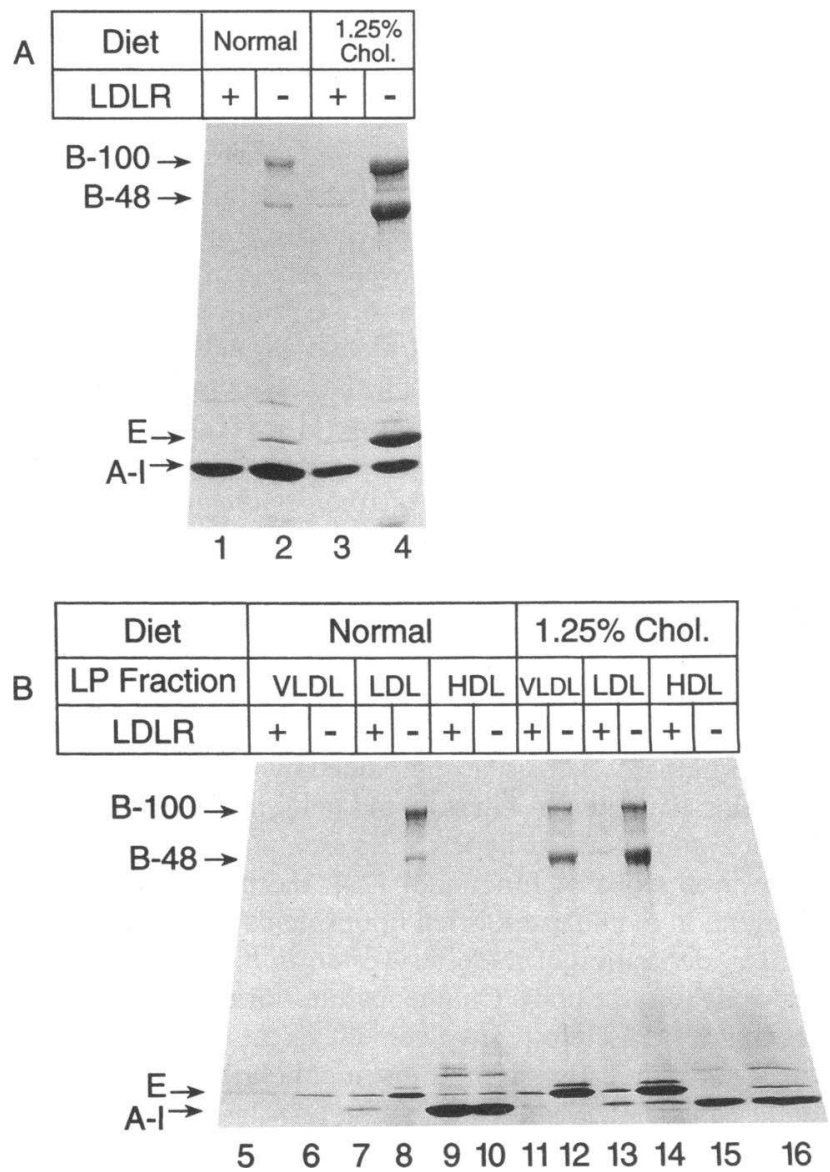

Figure 2. SDS-PAGE of apolipoproteins from lipoproteins of wild type and $L D L R^{-1-}$ mice fed different diets. Six mice (three males and three females) that were wild type $(+)$ or homozygous for the disrupted LDL receptor allele (-) were fed a normal chow diet (lanes 1,2 , and $5-10$ ) or a diet containing $1.25 \%$ cholesterol (lanes 3, 4, and $11-16)$ for $6 \mathrm{mo}$. $(A)$ The total lipoprotein fraction of plasma ( $d$ $<1.215 \mathrm{~g} / \mathrm{ml}$ ) was delipidated with ethanol/ether, and an aliquot corresponding to $30 \mu \mathrm{l}$ plasma was subjected to electrophoresis on $5-20 \%$ SDS gradient gels. $(B)$ The apoproteins from the peak tube in the VLDL, IDL/LDL, and HDL containing fractions (equivalent to $24 \mu$ l of plasma ) in Fig. 1 were delipidated and subjected to SDSPAGE. Proteins were stained with Coomassie blue, and the intensity of the bands was estimated by densitometric scanning. The gels were calibrated with Rainbow ${ }^{\mathrm{TM}}$ Protein Molecular Weight Markers (Amersham Corp., Arlington Heights, IL). The positions of migration of apo B-100, apo B-48, apo E, and apo A-I are indicated. 

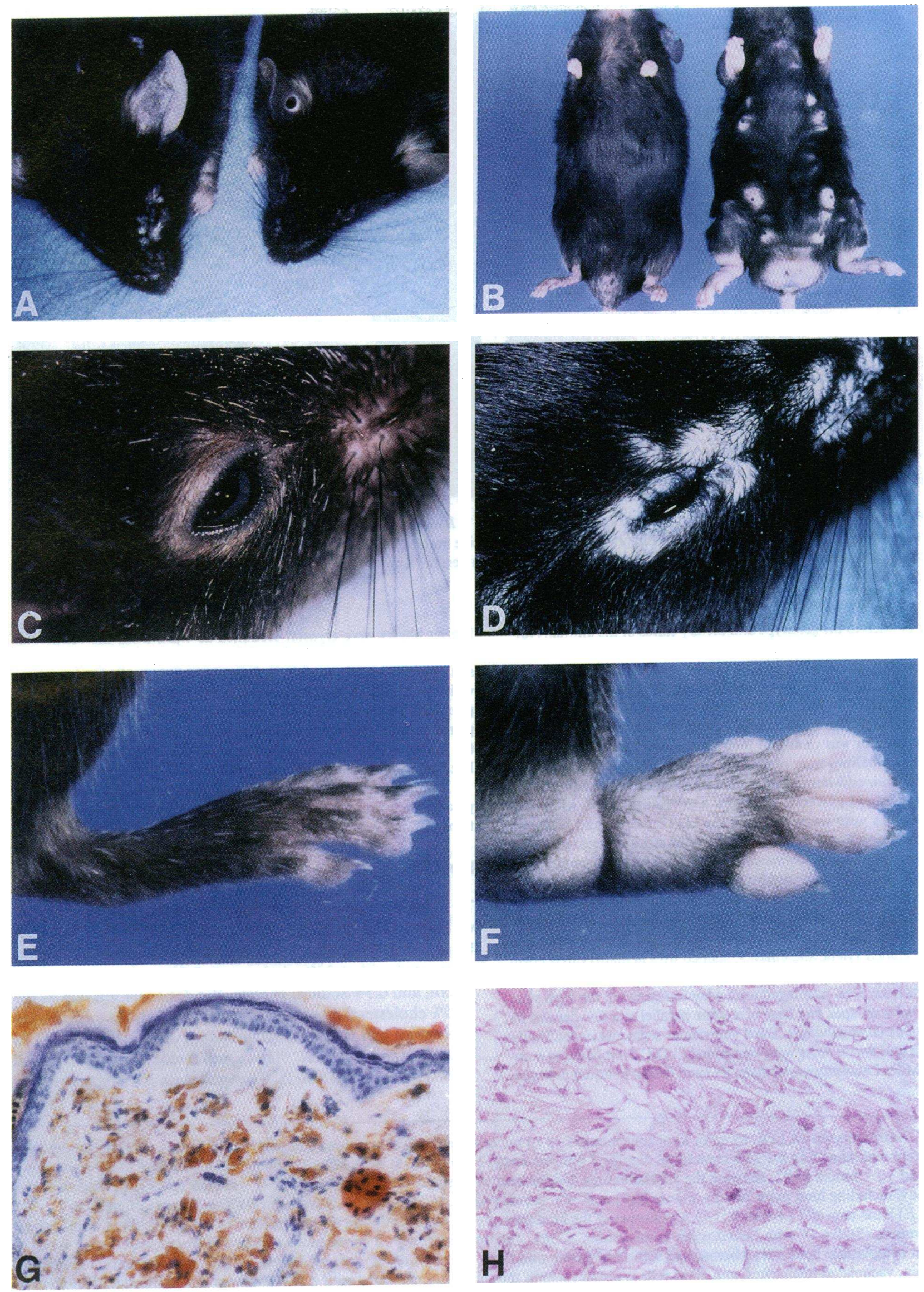

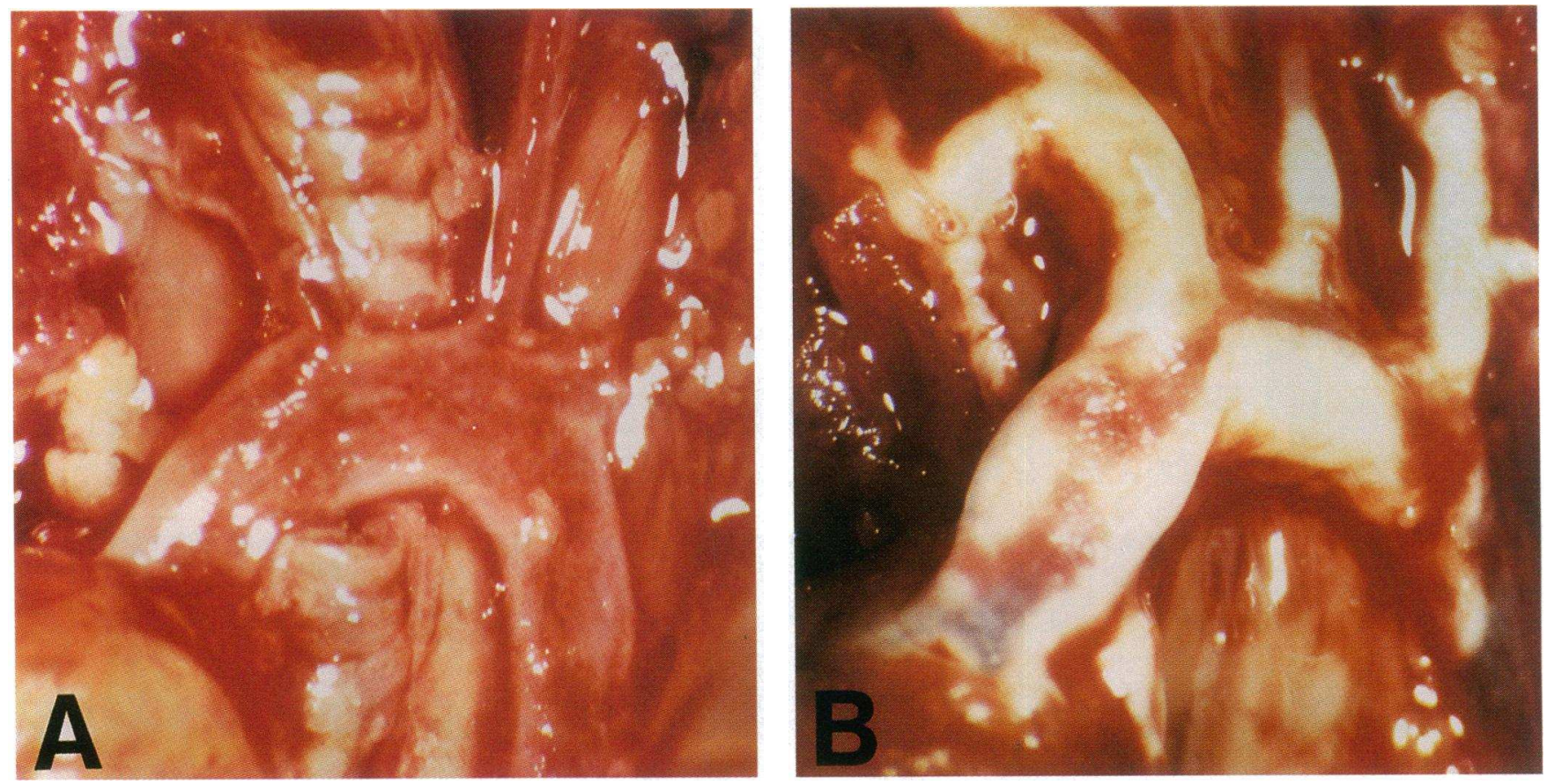

Figure 4. In situ photograph of aortic arches of wild type $(A)$ and $L D L R^{-1-}(B)$ mice that had been fed a $1.25 \%$ cholesterol diet for 8 mo. The mice (males) were $13 \mathrm{mo}$ of age at the time of the photograph. $(B)$ Extensive aortic plaque formation is visible through the thin aortic wall, involving the aortic arch as well as the proximal portions of major branch vessels. The total plasma cholesterol levels in the wild type and $L D L R^{-1-}$ mice were 173 and $1,893 \mathrm{mg} / \mathrm{dl}$, respectively.

observer blinded to the genotype and dietary status of the animal. Aortas were transected immediately proximal to the origin of the brachiocephalic artery, opened longitudinally, and pinned. The entire aorta was rinsed briefly in $70 \%$ ( $\mathrm{vol} / \mathrm{vol})$ ethanol, then immersed in $0.5 \%$ (wt/vol) Sudan IV in 35\% ethanol/50\% acetone for 15 min with continuous shaking. The aorta was destained in $80 \%$ ethanol until the background color was clear and then washed with water (13). Gross intimal abnormalities were noted and photographed.

Hearts from odd-numbered mice were fixed by immersion in $10 \%$ ( vol/vol) neutral buffered formalin for a minimum of $3 \mathrm{~d}$. After fixation, ventricles were transected midway between apex and base in a plane parallel to a line defined by the tips of the atrial appendages. Basal ventricular segments, in continuity with atria and aortic roots, were dehydrated, embedded in paraffin and serially sectioned at $6 \mu \mathrm{m}$ from ventricle through the aortic root and ascending aorta, encompassing both coronary ostia, the coronary sinuses, and the aortic valve leaflet, parallel to the plane described above. Every 10th section was rehydrated in graded xylene and ethanol, stained with hematoxylin \& eosin (H\&E), and examined by light microscopy.

Hearts from even-numbered mice were transected in the fresh state midway between apex and base in a plane parallel to a line defined by the tips of atrial appendages. Basal ventricular segments in continuity with atria and aortic roots were embedded in O.C.T embedding compound (Miles Laboratories, Elkhart, IN) and frozen in liquid nitrogen.
Frozen blocks were cryostat sectioned at $4 \mu \mathrm{m}$ from the ventricular margin to the aortic root in a plane parallel to the original plane of the section. Initial sections were captured at $\sim 200-\mu \mathrm{m}$ intervals, stained with H\&E, and immediately examined by light microscopy to assess proximity to the aortic root. Upon identification of the aortic root, paired sections through both coronary ostia, the coronary sinuses, and the aortic leaflets were captured at $\sim 40-\mu \mathrm{m}$ intervals, stained with H\&E and Sudan IV/hematoxylin, and examined by light microscopy.

Xanthomas were evaluated histologically using both frozen and paraffin sections and stained in the same manner as the cardiac sections.

\section{Results}

To stress the lipoprotein transport system in $L D L R^{-/-}$mice, we chose the atherogenic diet that was developed for mice by Paigen et al. (14). This diet contains normal mouse chow supplemented with $1.25 \%$ cholesterol, $7.5 \%$ cocoa butter, $7.5 \%$ casein, and $0.5 \%$ sodium cholate. We designate this diet as the $1.25 \%$ cholesterol diet. After 2 wk on this diet, the total plasma cholesterol had risen dramatically to levels $>1,500 \mathrm{mg} / \mathrm{dl}$ in male and female $L D L R^{-1-}$ mice, but it remained $<160 \mathrm{mg} / \mathrm{dl}$ in wild type mice (Table I). The total plasma triglyceride levels

Figure 3. Xanthomas in an LDL receptor knockout mouse $(-/-)$ as compared with a xanthoma-free wild type mouse $(+/+)$. Both mice (females) were maintained on a $1.25 \%$ cholesterol diet for 7 mo and were 12 mo of age at the time of the photograph. $(A)$ Face of $+/+$ mouse (right) and $-1-$ mouse (left), showing the xanthomatous involvement of ears and xanthelasmas in the $-/-$ mouse. $(B)$ Ventral aspect of the lower body, including hind paws, of $+/+$ mouse (left) and $-/-$ mouse $($ right $)$. (C) Eyelid of $+/+$ mouse. $(D)$ Xanthelasma of eyelid in $-/-$ mouse. $(E)$ Hind paw of $+/+$ mouse. $(F)$ Xanthomas of the hind paw of $-/-$ mouse. $(G)$ Microscopic section of the xanthelasma from eyelid of $-1-$ mouse (Sudan IV with hematoxylin counterstain; $\times 250$ ). The dermis contains a conspicuous infiltrate of macrophages laden with abundant cytoplasmic lipid. $(H)$ Microscopic section of xanthomas from hind paw of $-/-$ mouse $(\mathrm{H} \& \mathrm{E} ; \times 250)$. A prominent infiltrate of lipid-laden, vacuolated histiocytes, and giant cells is present within the soft tissue associated with cleft-like spaces that mark sites of cholesterol crystal deposition. The total plasma cholesterol levels in the $+/+$ mice ranged from 190 to $264 \mathrm{mg} / \mathrm{dl}$; the values in the $-/-$ mice ranged from 1,961 to $2,360 \mathrm{mg} / \mathrm{dl}$. 
did not change significantly. The mean values for wild type mice (males and females combined) decreased slightly from 129 to $102 \mathrm{mg} / \mathrm{dl}$ on the atherogenic diet. In the $L D L R^{-1-}$ mice, the mean values increased slightly from 142 to $157 \mathrm{mg} / \mathrm{dl}$.

After 6 mo on the $1.25 \%$ cholesterol diet, the $L D L R^{-1-}$ mice exhibited a massive increase in cholesterol contained in VLDL and LDL as determined by gel filtration chromatography (Fig. $1 B$ ). An elevation was also observed in lipoproteins with sizes between those of VLDL and LDL, which represent VLDL remnants or IDL. In wild type mice, the VLDL, IDL, and LDL cholesterol levels also rose, but their levels were $<1$ / 20 th of the levels seen in the $L D L R^{-/-}$mice (Fig. $1 A$ ). Wild type as well as $L D L R^{-/-}$mice exhibited a marked decline in cholesterol contained in HDL.

To determine the effects of the $1.25 \%$ cholesterol diet on the total amount of apoproteins in plasma, we performed SDSPAGE on the total lipoprotein fraction (Fig. $2 A$ ). On a normal diet the levels of apo B-100, apo B-48, and apo E were markedly elevated in the $L D L R^{-1-}$ mice as compared with the wild type mice (compare lanes 2 and 1 ). These levels increased further when the $L D L R^{-1-}$ mice were fed the $1.25 \%$ choles- terol diet (lane 4). The relative effect of the diet on apo B-48 was greater than on apo B-100. Thus, the ratio of apo B-48 to apo B-100 increased from 0.2 in the chow-fed $L D L R^{-1-}$ mice (lane 2) to 1.0 in the cholesterol-fed $L D L R^{-/-}$mice (lane 4).

The three apoproteins (apo B-48, apo B-100, and apo-E) that were elevated by cholesterol feeding in the $L D L R^{-1-}$ mice were found in the VLDL and LDL fractions as defined by gel filtration (Fig. $2 \mathrm{~B}$ ). They were also found in the IDL fractions (data not shown).

Among wild type animals maintained on normal chow and $1.25 \%$ cholesterol diets, no gross lesions of xanthomatosis or atherosclerosis were detected externally (Fig. 3, $A, B, C$, and $E$ ) or in the aortic arch in situ (Fig. $4 A$ ). Sudan IV-stained aortas from wild type mice maintained on a $1.25 \%$ cholesterol diet for 8 mo (Fig. $5 \mathrm{C}$ ) retained the normal translucent quality of age-matched wild type animals fed a normal control diet (Fig. 5 A). Similarly, among $L D L R^{-1-}$ mice fed a normal diet for up to $13 \mathrm{mo}$, no gross aortic lesions were detectable (Fig. $5 \mathrm{~B}$ ).

In contrast, $L D L R^{-1-}$ animals maintained on a $1.25 \%$ cholesterol diet for 7 mo developed conspicuous xanthelasma, xanthomatous infiltration of the ears, ventral xanthomas, and
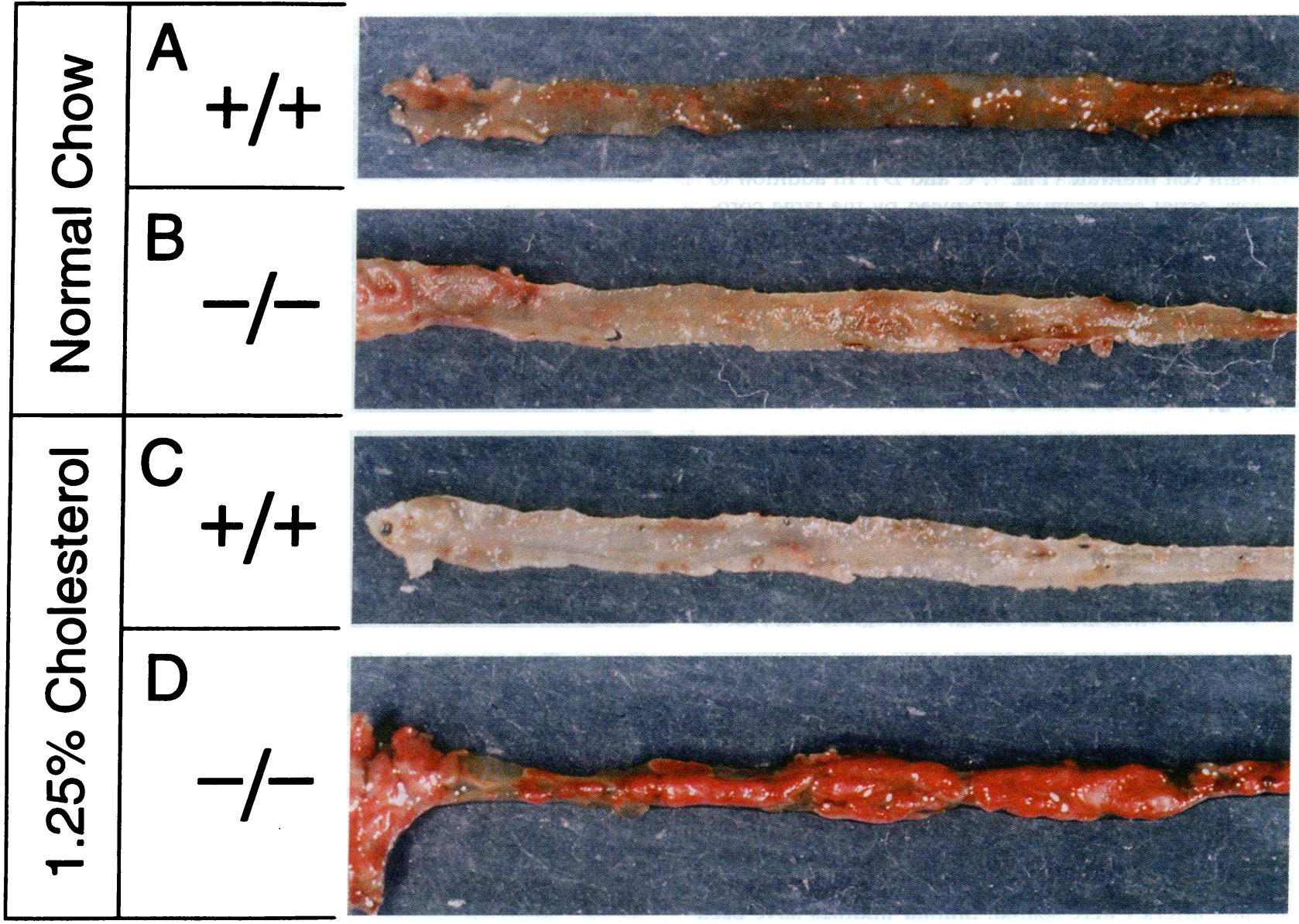

Figure 5. Photographs of luminal surface of aortas from wild type mice ( $A$ and $C$ ) and $L D L R^{-1-}$ mice $(B$ and $D)$ stained for lipid with Sudan IV. Male mice were fed the indicated diet for $8 \mathrm{mo}$ and were $13 \mathrm{mo}$ of age at the time of the photographs. $(A)$ Wild type mouse fed a normal chow diet ( total plasma cholesterol, $125 \mathrm{mg} / \mathrm{dl}$ ). (B) $L D L R^{-1-}$ mouse fed a normal chow diet (plasma cholesterol, $277 \mathrm{mg} / \mathrm{dl}$ ). (C) Wild type mouse fed a $1.25 \%$ cholesterol diet (plasma cholesterol, $225 \mathrm{mg} / \mathrm{dl}$ ). (D) $L D L R^{-1-}$ mouse fed a $1.25 \%$ cholesterol diet (plasma cholesterol, 1,893 $\mathrm{mg} / \mathrm{dl}) .(A-C)$ Intimal surfaces from both wild type mice and the $L D L R^{-1-}$ mouse maintained on a normal chow diet retain a glistening, translucent quality, with only small deposits of adventitial fat visible. The aorta in $D$ contains prominent elevated lipid-rich plaques over most of its length. 
footpad thickening (Figs. 3, $A, B, D$, and $F$ ). The lesions became clinically apparent 5 mo after initiation of feeding. Histological examination confirmed the presence of abundant $\mathrm{Su}-$ dan IV-stainable lipid within the eyelid xanthelasma of such animals (Fig. $3 G$ ), and a vigorous xanthogranulomatous reaction was seen in the soft tissues of the footpads (Fig. $3 \mathrm{H}$ ). The aortas from such $L D L R^{-/-}$mice contained well-developed atheromas, readily visible upon exposure of the aortic arch in situ (Fig. $4 \mathrm{~B}$ ). Sudan IV stains of whole aortas from these animals confirmed the presence of prominent, lipid-rich atheromas involving virtually the entire length of the vessel (Fig. $5 \mathrm{D}$ ).

Histological examination of the aortic roots of $L D L R^{-1-}$ mice demonstrated small accumulations of intimal foam cells within the walls of the coronary sinuses in animals fed normal chow for 12 mo (Fig. 6, $A-C$ ). No abnormalities were detected microscopically in age-matched wild type animals maintained on the same diet (data not shown).

Among wild type animals maintained 7 mo on a $1.25 \%$ cholesterol diet, histological sections of the aortic root demonstrated good preservation of aortic wall and valve morphology (Fig. $7 A$ ), with only occasional, minute lipid deposits apparent in Sudan IV-stained sections. In striking contrast, histological examination of the aortic roots of $L D L R^{-/-}$animals maintained on a $1.25 \%$ cholesterol diet for 7 mo demonstrated massive atheromatous deposits within the proximal aorta, which in some cases virtually occluded the coronary sinuses (Fig. $7 \mathrm{~B}$ ). The morphology of the aortic lesions was that of a typical atheroma with a well-developed, lipid-rich core and an accompanying foam cell infiltrate (Fig. 7, $C$ and $D$ ). In addition to the coronary ostial compromise produced by the large coronary sinus atheromas, atheromatous plaques extended into the proximal lumens of both right and left coronary arteries (Fig. 8 $A$ ). Distal coronary plaques or foam cells, however, were not found in any animals. In addition to the aortic changes noted, atheromatous plaques were invariably present in the main pulmonary trunks of $L D L R^{-/-}$after 8 mo of the cholesterol feeding (Fig. $8 \mathrm{~B}$ ).

\section{Discussion}

The current data demonstrate that homozygous LDL receptor-deficient mice develop all of the cardinal manifestations of homozygous FH when they are fed an atherogenic diet rich in cholesterol, saturated fat, and cholic acid. The resemblance between the mouse and human pathology is striking. In both species cholesterol-loaded macrophages accumulate in skin and subcutaneous tissues, creating massive xanthomas.

In the $L D L R^{-1-}$ mice, arterial involvement appeared most severe at the root of the aorta and the ostia of the coronary arteries with variable degrees of xanthomatous change in the aortic valve leaflets. Atheromatous lesions were also detected in the pulmonary trunks of $L D L R^{-/-}$mice. Strikingly, the distal coronary arteries were spared. Similar findings have been reported in FH homozygotes $(1,15-18)$. A recent study of 49 South African FH homozygotes with the relatively mild receptor-defective form of the disease revealed that the aortic valve, root, and coronary ostia became severely atherosclerotic in the teenage years (18). Individuals who survived developed distal coronary artery disease after 20 yr of age. A similar progression appears to be the case in homozygous Watanabe-heritable hy-
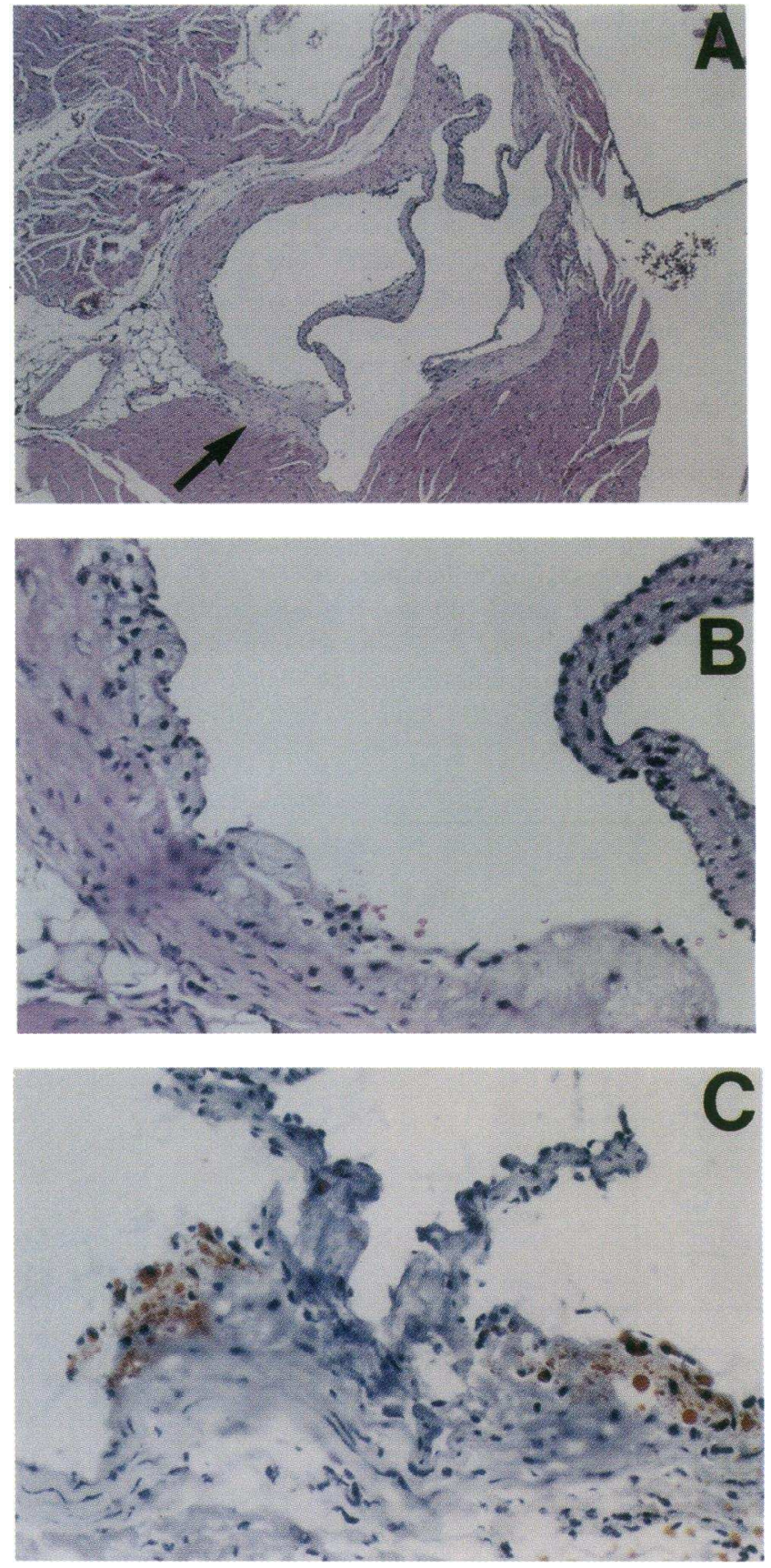

Figure 6. Photomicrographs of cross sections through the aortic valve attachment sites in $L D L R^{-1-}$ mice fed a normal chow diet. The mice (females) were $12 \mathrm{mo}$ of age at the time of the photograph. Their plasma cholesterol levels were $342 \mathrm{mg} / \mathrm{dl}$ in $A$ and $B$ and $262 \mathrm{mg} / \mathrm{dl}$ in $C$. ( $A)$ Small subendothelial lipid deposits are visible within the coronary sinus near one valve attachment site (arrow) (H\&E, $\times 50)$. $(B)$ Higher magnification of the lesion shown in $A$, demonstrating intimal foam cell accumulation in the wall of coronary sinus (H\&E, $\times 250)$. $(C)$ Cryostat section stained with Sudan IV and counterstained with hematoxylin. Intimal lipid deposits near point of valve attachment are stained red $(\times 250)$.

perlipidemic rabbits that lack LDL receptors (19). The $L D L R^{-1-}$ mice in the current study were followed for only 7-8 mo on the cholesterol diet. It will be important to follow these mice for longer periods to determine whether they develop distal coronary occlusions. 

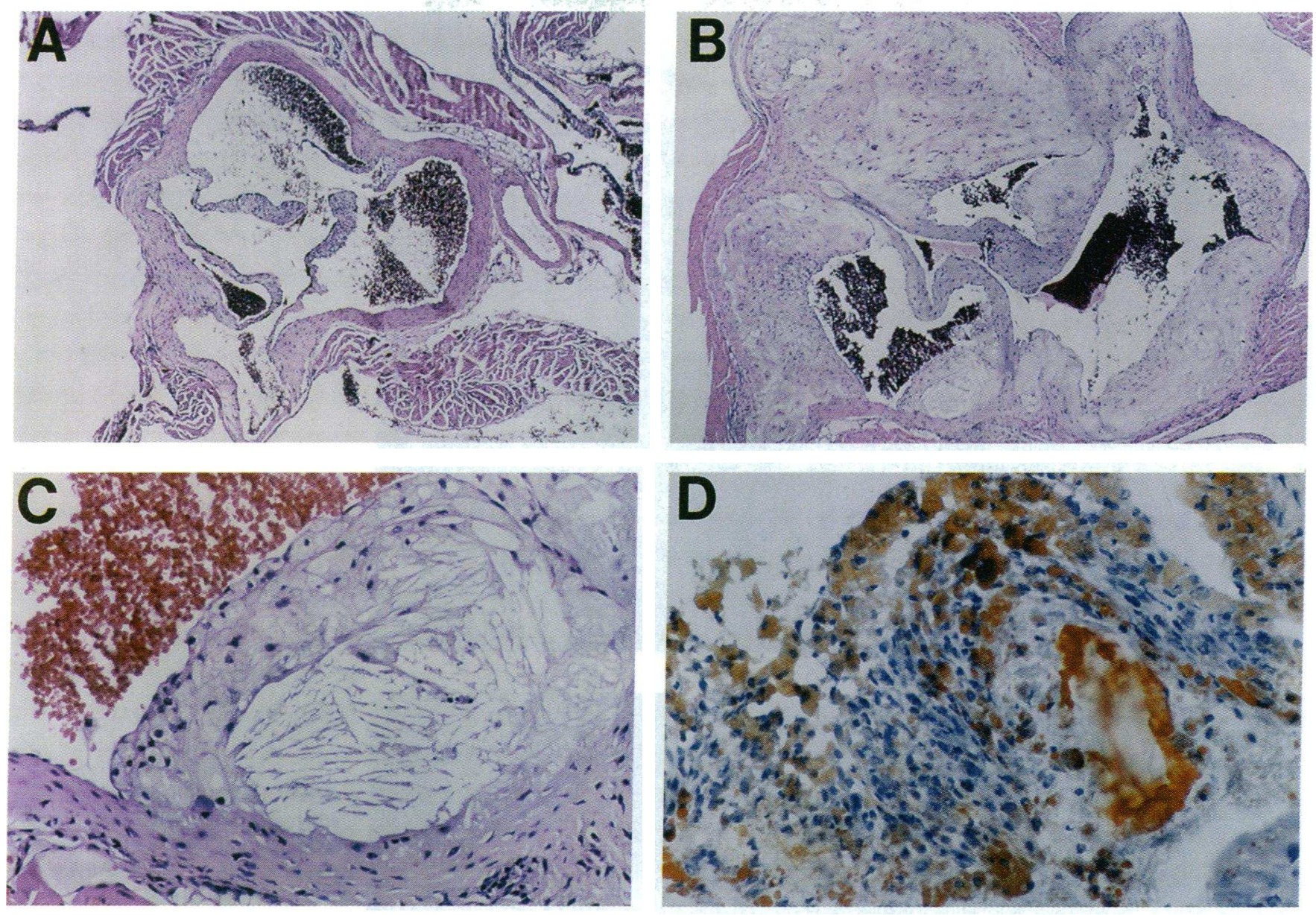

Figure 7. Atherosclerotic lesions in the coronary sinus of $L D L R^{-1-}$ mice $(B-D)$ as compared with a wild type mouse $(A)$ fed a $1.25 \%$ cholesterol diet for $7 \mathrm{mo}$. (A) Low-power photomicrograph of cross section of aortic root of wild type mouse at the level of the coronary sinus. The aortic root is of normal diameter, and no lipid deposits are visible within the walls of the coronary sinuses (H\&E, $\times 50$ ) (plasma cholesterol, $196 \mathrm{mg} /$ dl). (B) Low-power photomicrograph of cross section of aortic root of $L D L R^{-1-}$ mouse. The aortic root is ectatic, and the coronary sinuses and portions of the aortic valve leaflets contain massive atheromatous plaques (H\&E, $\times 50$ ) (plasma cholesterol, 2,308 $\mathrm{mg} / \mathrm{dl}$ ). (C) Higher magnification of advanced coronary sinus plaque shown in $B$. A prominent lipid core containing readily visible cholesterol clefts is present in the deeper region of the plaque, capped by well-preserved foam cells $(\mathrm{H} \& \mathrm{E}, \times 250) .(D)$ Cryostat section through aortic root of $L D L R^{-/-}$mouse. The Sudan IV stains lipid deposits in an advanced atheroma with a characteristic red color (Sudan IV with hematoxylin counterstain, $\times 250$ ) (plasma cholesterol, $1,974 \mathrm{mg} / \mathrm{dl}$ ).

The mechanism for the apparent proximal-to-distal spread of atherosclerosis in LDL receptor deficiency states is obscure. The earlier involvement of large diameter arteries may relate to hemodynamic factors. Alternatively, it may relate to different properties of the endothelium, smooth muscle cells, or connective tissue substances in larger vessels as compared with smaller ones.

The development of the cholesterol-fed $L D L R^{-/-}$mouse model of atherosclerosis may allow delineation of genes that control the atherosclerotic process. Certain strains of mice are more atherosclerosis prone than others when fed atherogenic diets $(14,20,21)$. One susceptibility gene has been traced to a single locus designated Ath-1 on mouse chromosome 1 (reference 22). It will be of interest to breed the $L D L R^{-/-}$mice with mice of different strains to search for additional genes that ameliorate atherosclerosis and xanthomatosis. The presence of striking external xanthomatosis provides an easy system to score mice for the inheritance of this trait.

The current observations may be compared with the pattern of atherosclerosis reported in mice in whom the gene for apo $\mathrm{E}$ has been disrupted $(23,24)$. On a chow diet these animals have higher total cholesterol levels than do the $L D L R^{-/-}$ mice ( $\sim 450$ vs. $235 \mathrm{mg} / \mathrm{dl}$ ), and they develop atherosclerosis of the aortic root and coronary ostia without the need for cholesterol feeding $(23,24)$. Although the hypercholesterolemia and atherosclerosis were made much worse when the apo $E^{-/-}$ mice were fed a diet that contains $0.15 \%$ cholesterol (24), xanthomatosis was not reported.

In the current study widespread xanthomatosis was observed in $13 L D L R^{-/-}$mice that were fed the $1.25 \%$ cholesterol diet for 7-10 mo. These animals had total plasma cholesterol levels that ranged from 1,304 to $2,893 \mathrm{mg} / \mathrm{dl}$ (mean, 2097 $\mathrm{mg} / \mathrm{dl}$ ). In studies not yet reported, apo $E^{-/-}$mice were fed a $1.25 \%$ cholesterol diet similar to that used in the current study. Even though the apo $E^{-/-}$mice manifested total plasma cholesterol levels in the range of $4,000 \mathrm{mg} / \mathrm{dl}$, they did not show gross evidence of cutaneous or tendon xanthomata after 3 mo ( $N$. Maeda, personal communication). This result raises the possibility that xanthomatosis is accelerated by some action of apo E. This apoprotein may act as an agent for lipoprotein uptake 

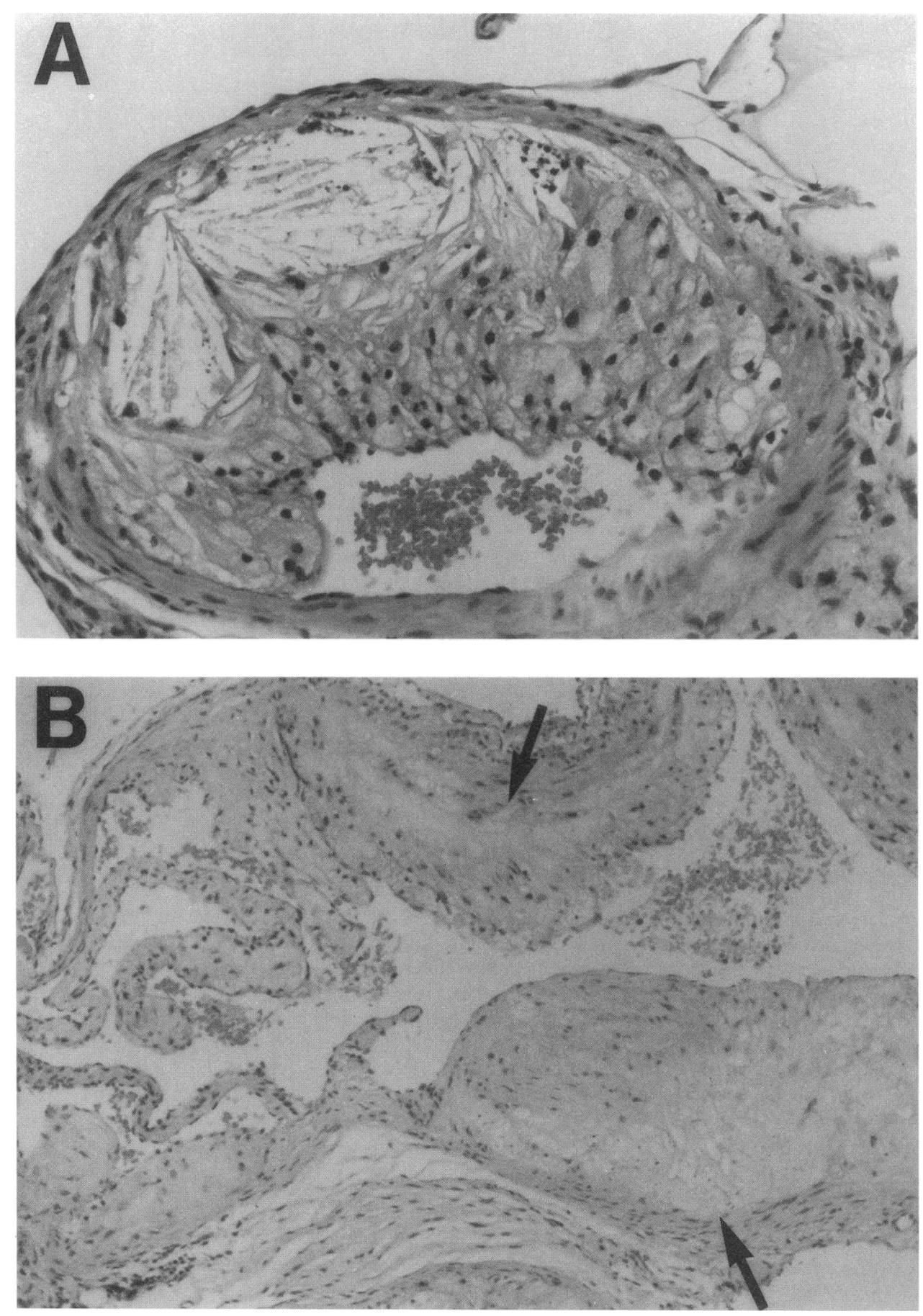

Figure 8. Photomicrographs of the atherosclerotic lesions in a coronary artery $(A)$ and a pulmonary artery (B) of a $L D L R^{-1-}$ mouse fed a $1.25 \%$ cholesterol diet for $8 \mathrm{mo}$. The male mouse was $13 \mathrm{mo}$ of age at the time of the photograph (total plasma cholesterol level, $1,893 \mathrm{mg} /$ dl). ( $A$ ) Cross section through left main coronary artery. Atheromatous lesions were present in the proximal portions of both right and left coronary arteries in animals with advanced coronary sinus lesions, but spared the more distal portions of the coronaries in all cases (H\&E, $\times 250)$. (B) Longitudinal section through pulmonic valve and main pulmonary artery. Prominent supravalvular atheromas (arrows) are present in the pulmonary artery (H\&E, $\times 50)$. in macrophages, or it might mediate lipoprotein adherence to connective tissue elements in tendon and skin.

\section{Acknowledgments}

We thank Laura Deane, Scott Clark, John Dawson, and Lucy Lundquist for excellent technical assistance.

This work was supported by National Institutes of Health grant HL-20948 and by grants from the W. M. Keck Foundation, Moss Heart Foundation, and the Perot Family Foundation. J. Herz is supported by the Syntex Scholar Program and is a Lucille P. Markey Scholar.

\section{References}

1. Goldstein, J. L., and M. S. Brown. 1989. Familial hypercholesterolemia. In The Metabolic Basis of Inherited Disease. C. R. Scriver, A. L. Beaudet, W. S. Sly, and D. Valle, editors. McGraw-Hill Inc., New York. 1215-1250.

2. Ishibashi, S., M. S. Brown, J. L. Goldstein, R. D. Gerard, R. E. Hammer, and J. Herz. 1993. Hypercholesterolemia in LDL receptor knockout mice and its reversal by adenovirus-mediated gene delivery. J. Clin. Invest. 92:883-893.

3. Higuchi, K., K. Kitagawa, K. Kogishi, and T. Takeda. 1992. Developmental and age-related changes in apolipoprotein B mRNA editing in mice. J. Lipid Res. 33:1753-1764.

4. Scott, J. 1989. The molecular and cell biology of apolipoprotein-B. Mol. Biol. Med. 6:65-80.

5. Chan, L. 1992. Apolipoprotein B, the major protein component of triglyceride-rich and low density lipoproteins. J. Biol. Chem. 267:25621-25624. 
6. Brown, M. S., and J. L. Goldstein. 1983. Lipoprotein receptors in the liver: Control signals for plasma cholesterol traffic. J. Clin. Invest. 72:743-747.

7. Havel, R. J. 1987. Lipid transport function of lipoproteins in blood plasma. Am. J. Physiol. 253:E1-E5.

8. Brown, M. S., J. Herz, R. C. Kowal, and J. L. Goldstein. 1991. The lowdensity lipoprotein receptor-related protein: double agent or decoy? Curr. Opin. Lipidol. 2:65-72.

9. Mahley, R. W. 1988. Apolipoprotein E: Cholesterol transport protein with expanding role in cell biology. Science (Wash. DC). 240:622-630.

10. Kita, T., J. L. Goldstein, M. S. Brown, Y. Watanabe, C. A. Hornick, and R. J. Havel. 1982. Hepatic uptake of chylomicron remnants in WHHL rabbits: a mechanism genetically distinct from the low density lipoprotein receptor. Proc. Natl. Acad. Sci. USA. 79:3623-3627.

11. Rubinsztein, D. C., J. C. Cohen, G. M. Berger, D. R. van der Westhuyzen, G. A. Coetzee, and W. Gevers. 1990. Chylomicron remnant clearance from the plasma is normal in familial hypercholesterolemic homozygotes with defined receptor defects. J. Clin. Invest. 86:1306-1312.

12. Van't Hooft, F. M., D. A. Hardman, J. P. Kane, and R. J. Havel. 1982. Apolipoprotein B ( B-48) of rat chylomicrons is not a precursor of the apolipoprotein of low density lipoproteins. Proc. Natl. Acad. Sci. USA. 79:179-182.

13. Holman, R. L., H. C. McGill, Jr., J. P. Strong, and J. C. Geer. 1958. Technics for studying atherosclerotic lesions. Lab. Invest. 7:42-47.

14. Paigen, B., A. Morrow, C. Brandon, D. Mitchell, and P. Holmes. 1985 Variation in susceptibility to atherosclerosis among inbred strains of mice. Atherosclerosis. 57:65-73.

15. Buja, L. M., P. T. Kovanen, and D. W. Bilheimer. 1979. Cellular pathology of homozygous familial hypercholesterolemia. Am. J. Pathol. 97:327-357.
16. Hendry, W. G., and M. Seed. 1985. Homozygous familial hypercholesterolaemia with supravalvular aortic stenosis treated by surgery. J. Royal Soc. Med. 78:334-335.

17. Allen, J. M., G. R. Thompson, N. B. Myant, R. Steiner, and C. M. Oakley 1980. Cardiovascular complications of homozygous familial hypercholesterolaemia. Br. Heart J. 44:361-368.

18. Haitas, B., S. G. Baker, T. E. Meyer, B. I. Joffe, and H. C. Seftel. 1990. Natural history and cardiac manifestations of homozygous familial hypercholesterolaemia. $Q$. J. Med. (new series) 76:731-740.

19. Buja, L. M., T. Kita, J. L. Goldstein, Y. Watanabe, and M. S. Brown. 1983. Cellular pathology of progressive atherosclerosis in the WHHL rabbit, an animal model of familial hypercholesterolemia. Arteriosclerosis. 3:87-101.

20. Lusis, A. J. 1993. The mouse model for atherosclerosis. Trends Cardiov. Med. 3:135-143.

21. Ishida, B. Y., and B. Paigen. 1989. Atherosclerosis in the mouse. In Genetic Factors in Atherosclerosis: Approaches and Model Systems. A. J. Lusis and S. R. Sparkes, editors. Karger, Basel. 189-222.

22. Paigen, B., D. Mitchell, K. Reue, A. Marrow, A. J. Lusis, and R. C. LeBoeuf. 1987. Ath-1, a gene determining atherosclerosis susceptibility and high density lipoprotein levels in mice. Proc. Natl. Acad. Sci. USA. 84:3763-3767.

23. Zhang, S. H., R. L. Reddick, J. A. Piedrahita, and N. Maeda. 1992. Spontaneous hypercholesterolemia and arterial lesions in mice lacking apolipoprotein E. Science (Wash. DC). 258:468-471.

24. Plump, A. S., J. D. Smith, T. Hayek, K. Aalto-Setälä, A. Walsh, J. G. Verstuyft, E. M. Rubin, and J. L. Breslow. 1992. Severe hypercholesterolemia and atherosclerosis in apolipoprotein $\mathrm{E}$ deficient mice created by homologous recombination in ES cells. Cell. 71:343-353. 